Jurnal Skripta, Volume 5, No 1, Februari 2019

\title{
ANALISIS NILAI KARAKTER DALAM WAYANG KULIT DENGAN LAKON PUSPITO MANIK SEBAGAI SUMBER BELAJAR SASTRA SISWA SMP
}

\author{
Tri Ratna Herawati \\ Prodi Pendidikan Bahasa dan Sastra Indonesia \\ Universitas PGRI Yogyakarta \\ trherawati@yahoo.com
}

\begin{abstract}
Abstrak: Upaya peningkatan implementasi nilai karakter bagi siswa SMP telah dilakukan dengan berbagai cara, termasuk melalui proses pembelajaran Bahasa Indonesia menggunakan media wayang kulit. Wayang kulit merupakan peninggalan nenek moyang selain berperan sebagai tontonan, namun juga mengandung tatanan dan tuntunan. Penelitian ini bertujuan untuk menganalisis terhadap nilai karakter yang terkandung dalam wayang kulit dengan lakon Puspito Manik. Untuk memperoleh data penelitian ini dilakukan melalui tahapan menganalisis nilai karakter yang dimiliki oleh setiap tokoh dalam lakon tersebut. Berdasarkan hasil penelitian diperoleh kesimpulan bahwa wayang kulit berperan sebagai tontonan, sekaligus tuntunan. Tontonan karena wayang kulit dapat dinikmati oleh seluruh lapisan masyarakat, sedangkan tuntunan karena mengandung pesan moral yang disampaikan oleh seorang dalang yang terkait dengan perilaku bermasyarakat, termasuk berbangsa dan bernegara bahkan juga terkait dengan bela negara. Seluruh nilai karakter yang meliputi: 1) religius, 2) jujur, 3) toleransi, 4) disiplin, 5) kerja keras, 6) kreatif, 7) mandiri, 8) demokratis, 9) rasa ingin tahu, 10) semangat kebangsaan, 11) cinta tanah air, 12) menghargai prestasi, 13) bersahabat/komunikatif, 14) cinta damai, 15) gemar membaca, 16) peduli lingkungan, 17) peduli sosial, serta 18) tanggung jawab terkandung di dalam wayang kulit dengan Lakon Puspito Manik yang diperankan oleh masing-masing tokoh.
\end{abstract}

Kata kunci: Nilai Karakter, Wayang Kulit, Lakon Puspito, Sastra

\section{ANALYSIS OF CHARACTER VALUE IN SKIN WAYANG WITH MANIK PUSPITO AS A RESOURCES FOR SMP STUDENT LITERATURE LEARNING}

Abstract: Efforts to increase the implementation of character values for junior high school students have been carried out in various ways, including through the Indonesian language learning process using wayang kulit media. Wayang kulit is a legacy from our ancestors, besides serving as a spectacle, it also contains order and guidance. This study aims to analyze the character values contained in the shadow puppets with the play Puspito Manik. To obtain data, this research was carried out through the stages of analyzing the character values possessed by each character in the play. Based on the research results, it is concluded that the shadow puppets act as a spectacle, as well as a guide. The spectacle because wayang kulit can be enjoyed by all levels of society, while guidance because it contains a moral message conveyed by a puppeteer which is related to social behavior, including national and state and even also related to defending the state. All character values include: 1) religious, 2) honest, 3) tolerance, 4) discipline, 5) hard work, 6) creative, 7) independent, 8) democratic, 9) curiosity, 10) national spirit, 11) love the country, 12) respect achievement, 13) friendly / communicative, 14) love peace, 15) love reading, 16) care for the environment, 17) care about social, and 18) responsibility is contained in the shadow puppet with the Puspito play The beads are played by each character.

Keywords: Character Values, Wayang Kulit, Lakon Puspito, Literature 


\section{PENDAHULUAN}

Perkembangan ilmu pengetahuan, teknologi dan seni (IPTEKS) mampu mempengaruhi segala aspek kehidupan manusia, baik di negara berkembang maupun di negara maju, juga bagi kaum dewasa maupun kaum remaja. Kejadian penyimpangan yang dilakukan oleh remaja seperti seks bebas, tawuran, maupun ditemukannya beberapa video porno menunjukkan terjadinya degradasi moral di lingkungan kaum remaja. Kondisi yang seperti ini menimbulkan kecurigaan masyarakat mengenai kegagalan pendidikan. Kejadian kemerosotan moral dan penurunan sikap toleransi antar anggota masyarakat memunculkan kegelisahan bagi para praktisi di bidang pendidikan.

Berbagai upaya telah dilakukan agar tujuan pendidikan nasional sedapat mungkin segera dapat dicapai. Proses pendidikan selain dilakukan secara formal di sekolah, peran keluarga dan masyarakat juga tidak dapat diabaikan. Keluarga memiliki peran yang sangat penting di dalam menanamkan nilai moral, agama dan etika bagi generasi penerus. Kehidupan anak sebagian besar waktunya dihabiskan di lingkungan keluarga, sehingga peran keluarga tidak dapat diabaikan dalam membentuk karakter. Pendidikan di lingkungan keluarga disinyalir belum mampu memberikan kontribusi yang cukup dalam mendukung pencapaian kompetensi dan pembentukan karakter peserta didik. Bahkan di era sekarang ini banyak orang tua yang menyerahkan pendidikan sepenuhnya kepada sekolah. Selain itu banyak pula orang tua yang memiliki pengetahuan yang tidak mencukupi dalam mendidik anak secara baik dan benar. Untuk itu dirasa perlu peran serta sekolah dalam mendukung pendidikan karakter bagi generasi penerus.

Era global ditengarahi dengan mudahnya akses segala informasi yang terjadi di seluruh belahan dunia. Jaringan internet, televisi, serta telefon mobil mampu mendukung terciptanya kondisi remaja yang semakin baik maupun semakin banyak melanggar norma sosial. Filter terhadap masuknya budaya yang tidak sesuai perlu ditingkatkan. Media itu dapat menjadikan masyarakat melek informasi, namun bila tidak hati-hati dapat mengantarkan kehancuran suatu bangsa.

Sebagai salah satu langkah untuk meningkatkan kualitas pendidikan karakter perlu diupayakan untuk mengintegrasikan pendidikan karakter baik di dalam semua mata pelajaran formal, kegiatan ekstrakurikuler di sekolah maupun di dalam lingkungan keluarga. Harapan dari proses integrasi pendidikan karakter ini dapat dihasilkan manusia yang mampu mengembangkan kemampuannya serta tanggung jawab sosialnya.

Sehubungan dengan itu perlu mengajarkan Bahasa Indonesia dengan cara bervariasi, serta mengintegrasikan pendidikan karakter di dalamnya. Untuk memfasilitasi proses pembelajaran Bahasa Indonesia yang baik, guru memerlukan pembelajaran Bahasa Indonesia yang selain berorientasi untuk mencerdaskan peserta didik juga harus mampu meningkatkan nilai karakter peserta didik secara sinergis untuk menghasilkan insan yang beriman melalui analisis karya sastra yang bermuatan pendidikan karakter, seperti wayang kulit. Untuk itu dipandang perlu menggunakan wayang kulit dengan lakon Puspito Manik sebagai media untuk mengajarkan pendidikan karakter bagi peserta didik.

\section{TINJAUAN PUSTAKA}

Pendidikan karakter merupakan istilah yang digunakan untuk menjelaskan aspek pembelajaran untuk mengembangkan kepribadian peserta didik. Otten (2000) menyatakan bahwa "character education is an umbrella term used to describe many aspects of teaching and learning for personal 
development". Santrock (2014) memberi penjelasan mengenai pendidikan karakter, antara lain "character education is a direct approach to moral education that involves teaching students basic moral literacy to prevent them from engaging in immoral behavior and doing harm to them selves or other". Pendidikan karakter merupakan pendekatan langsung yang terkait dengan pendidikan moral. Pendidikan karakter berupaya untuk mengajar peserta didik dengan pengetahuan moral untuk mencegah melakukan perbuatan yang tidak bermoral, termasuk di dalamnya perbuatan yang membahayakan orang lain maupun diri sendiri. Perbuatan mencuri maupun membunuh merupakan perbuatan yang tidak bermoral, sehingga peserta didik harus mengetahuinya dan mengimplementasikannya.

Karakter merupakan gambaran mengenai tingkah laku yang mengutamakan nilai baik-buruk, maupun benar-salah yang dilakukan secara terang-terangan maupun sembunyi. Pendidikan karakter di Indonesia merupakan gerakan nasional sesuai dengan anjuran presiden Republik Indonesia, Susilo Bambang Yudoyono. Gerakan nasional ini berupaya untuk mendidik mengenai etika, tanggung jawab, dan kepedulian. Nilai etika utama dalam pendidikan karakter antara lain menghargai diri sendiri dan orang lain, disiplin, integritas, dan bertanggung jawab. Proses pendidikan karakter memerlukan waktu yang cukup panjang, bahkan hingga berlangsung bertahun-tahun. Pendidikan karakter ini juga dapat ditujukan untuk mengurangi perilaku peserta didik yang tidak disiplin seperti membolos maupun tawuran antara sekolah, pergaulan bebas, bahkan karakter peserta didik yang kurang semangat di dalam mengikuti proses pembelajaran. Pendidikan karakter ini berupaya untuk mengintegrasikan nilai-nilai positif di dalam setiap mata pelajaran maupun aktivitas sehari-hari.
Pendidikan karakter mempercayai adanya keberadaan moral absolut. Moral absolut ini perlu diajarkan kepada peserta didik agar mengetahui sesuatu yang baik dan benar (Kilpatrick, 1992; Lickona, 1992). Paham yang menganut moral absolut tidak menyetujui adanya pendidikan moral reasoning dan value classification, karena beranggapan adanya nilai moral universal yang bersifat absolut (bukan bersifat relatif). Nilai moral universal ini bersumber dari ajaran agama di dunia yang dikenal sebagai the golden rule. Beberapa nilai moral universal antara lain jujur, hormat, dan bertanggung jawab (Martiano, 2008).

Sebanyak tiga komponen karakter yang baik (components of good character), meliputi pengetahuan tentang moral (moral knowing), perasaan tentang moral (moral feeling), dan perbuatan bermoral (moral action) (Lickona, 1992). Komponen moral itu sangat penting untuk diketahui oleh peserta didik agar mampu memahami, merasakan, maupun mengerjakan nilai-nilai yang baik. Secara rinci Lickona (1992) menjelaskan bahwa terdapat 6 tujuan diajarkannya moral knowing, yaitu: 1) moral awareness, 2) knowing moral values, 3) perspective taking, 4) moral reasoning, 5) decision making, serta 6) self knowledge. Selain itu juga terdapat sebanyak 6 aspek emosi yang dapat dirasakan seseorang untuk menjadi manusia berkarakter, yaitu: 1) conscience, 2) self-esteem, 3) empathy, 4) loving the good, 5) self control, serta 6) humility. Tindakan moral merupakan hasil dari 2 karakter yang lain. Untuk mengetahui dorongan seseorang untuk berbuat baik (act morally) harus dilihat dari aspek lain dari karakter, yaitu: 1) kompetensi (competence), 2) keinginan (will), serta 3) kebiasaan (habit). Komponen karakter itu harus diajarkan kepada peserta didik melalui pendidikan karakter. Nilai yang terkandung di dalam pendidikan karakter terdiri dari nilai agama, 
nilai moral, nilai umum, dan nilai kewarganegaraan.

Karakter mulia yang sebaiknya diajarkan kepada peserta didik sebanyak 9 buah yang dikenal sebagai 9 pilar. Karakter mulia yang dimaksud meliputi:1) Cinta Tuhan dan kebenaran (love Allah, trust, reverence, loyalty), 2) Tanggung jawab, kedisiplinan, dan kemandirian (responsibility, excellence, self reliance, orderliness), 3) Amanah (trusthinnes, realibility, honesty), 4) Hormat dan santun ( respect, courtesy, obedience), 5) Kasih sayang, kepedulian, dan kerja sama (love, compassion, caring, empathy, generousity, moderation, cooperation), 6) Percaya diri, kreatif, dan pantang menyerah (confidence, assertiveness, creativity, resourcefulness, courage, determination and enthusiasm), 7) Keadilan dan kepemimpinan (justice, fairness, mercy, leadership), 8) Baik dan rendah hati (kindness, friendliness, humality, modesty), serta 9) Toleransi dan cinta damai (tolerance, flexibility, peacefulness, unity) (Megawangi, 2008).

\section{METODE PENELITIAN}

Penelitian ini merupakan penelitian deskriptif kualitatif. Subyek penelitian adalah wayang kulit lakon Puspito Manik, sedangkan subyek penilaian berupa pendidikan karakter yang terintegrasi di dalam pemaparan wayang kulit tersebut. Penelitian dilaksanakan di SMP provinsi Daerah Istimewa Yogyakarta yang dilaksanakan pada tahun 2013-2014. Instrumen yang digunakan berupa lembar observasi, dan lembar wawancara. Lembar observasi digunakan untuk menganalisis isi dari wayang kulit lakok Puspito Manik, sedangkan lembar wawancara digunakan untuk mewawancarai dalang yang kompeten.

Data penelitian yang berupa integrasi pendidikan karakter di dalam wayang kulit lakon Puspito Manik diawali dengan analisis karakter yang dimiliki oleh peserta didik di sekolah menengah. Kondisi riil ini dikorelasikan dengan pendidikan karakter yang terintegrasi dalam wayang kulit lakon Puspito Manik. Proses integrasi pendidikan karakter ini dikonsultasikan dengan dalang wayang kulit yang kompeten.

\section{HASIL DAN PEMBAHASAN}

Wayang kulit merupakan warisan budaya adiluhung yang ditinggalkan oleh nenek moyang bangsa Indonesia. Tujuan pementasan wayang kulit terutama digunakan sebagai media menyampaikan pesan dari pemberi pesan kepada masyarakat. Pesan yang diberikan dalam bentuk ajaran agama maupun informasi apapun yang harus disebarluaskan kepada masyarakat. Wayang memiliki makna bayangan, sehingga isi yang disampaikan melalui wayang kulit ini merupakan gambaran yang terjadi di masyarakat. Sebagai fasilitator untuk proses penyampaian informsi dilakukan oleh dalang. Wayang merupakan gambaran seseorang yang memiliki karakter yang tidak kontstan tergantung dari situasi yang dialami oleh seseorang.Ketika marah karakter yang menonjol berupa karakter raksana. Suatu saat ketika manusia mampu bersikap sabar, muncul sifat prabu Puntadewa raja Amarta yang bersikap sangat sabar.

\section{Sekuens Pertunjukan}

\section{a. Jejer Dworowati}

Janturan mengandung sanjungan yang berisi kehebatan maupun kesucian mereka. Janturan dilakukan oleh dalang ketika pada awal pementasan wayang kulit. Kondisi awal ini melambangkan seorang bayi yang tidak pernah melakukan kesalahan, sehingga isi janturan ini menyanjung maupun menceritakan kelebihan dari tokoh yang diceritakan dalam lakon yang bersangkutan.

Prabu Kresna dihadap oleh semua peragkat kerajaan di antaranya 
senopati negara yang bernama Raden Setyaki, serta patih negara yang selalu mendampingi raja yang bernama Patih Udawa. Raden Setyaki merupakan adik dari Prabu Kresna, sedangkan Patih Udawa merupakan anak dari Demang Antagopa yang memelihara Prabu Kresna beserta 2 saudaranya ketika masih kecil. Prabu Kresna, Prabu Baladewa dan Dewi Sembodro diungsikan oleh orang tuanya Prabu Basudewa untuk menghindari ancaman dari Kongsodewo anak tirinya. Pada awal pertemuan di istana Dworowati mereka saling menyapa dengan saling meminta serta memberi informasi mengenai keselamatan maupun kondisi masing-masing.

Pertemuan di istana Dworowati mendapat 2 orang tamu yang berasal dari negara Hastina. Tamu yang dimaksud yaitu seorang guru dan penasehat negara Hastina yaitu Pandita Durna, serta mahapatih di negara Hastina yang bernama Patih Haryo Sengkuni. Kedatangan keduanya bertujuan untuk meminjam Kembang Wijaya Kusuma dan permaisuri dari Prabu Kresna yang bernama Dewi Rukmini. Peminjaman dilakukan untuk mengatasi musibah (Jawa: pageblug) yang dialami masyarakat di negara Hastina. Masyarakat Hastina banyak yang meninggal dunia karena disebabkan oleh penyebab yang tidak jelas. Masyarakat mengalami sakit pagi hari, ternyata sorenya meninggal, sedangkan yang sakit sore hari umumnya meninggal pada pagi harinya. Kondisi ini menyebabkan kepanikan masyarakat. Untuk itu Prabu Duryudono raja Hastina memerintahkan kepada Mahapatih Haryo Sengkuni beserta penasehat Raja Hastina untuk mencari jalan agar malapetaka yang menimpa masyarakat
Hastina segera berakhir. Untuk itu 2 utusan dari negara Hastina mencari alternatif untuk mengatasi kondisi yang mencekam dengan mendatangi negara Dworowati untuk meminjam Kembang Wijaya Kusuma yang sangat terkenal memiliki kekuatan untuk menghidupkan manusia yang meninggal belum waktunya, maupun menyembuhkan penyakit berat.

Selain mendapat tamu Patih Haryo Sengkuni dan Pandita Durna, Raja Dworowati juga mendapat tamu dari kerajaan Tawang Gantungan bernama Dewo Kumoro. Dewo Kumoro ini merupakan raja yang diutus oleh Prabu Dewo Kusumo (raja Ngawu-awu Langit, negara seberang) yang memiliki tujuan yang sama dengan Pandita Durna dan Patih Haryo Sengkuni untuk meminjam Kembang Wijaya Kusuma dan isteri Prabu Kresna bernama Rukmini. Keinginan raja Dewo Kumoro ini sama dengan keinginan Patih Haryo Sengkuni dan Pandito Durno, yaitu mencari sarana untuk mengatasi kondisi negara yang terkena musibah seperti yang terjadi di negara Hastina. Setelah mengetahui maksud dan tujuan kedatangan Prabu Dewo Kumoro, Pandita Durna berusaha mencegah atau bahkan mengusir Prabu Dewo Kumoro yang memiliki keinginan yang sama dengan dirinya. Pandita Durna berfikir bila keinginan Prabu Dewo Kumoro dikabulkan oleh Prabu Kreno, niscaya keinginan yang bersangkutan pasti akan gagal karena sasaran yang diinginkan sama.

Setelah mendengar maksud dan tujuan dari para tamu yang berasal dari negara Hastina dengan yang berasal dari Kerajaan Ngawu-awu Langit, Prabu Kresna mengutus pada pembantu untuk mengecek kondisi pusaka 
Kembang Wijaya Kusuma dan Dewi Rukmini. Pembantu yang diutus memberi laporan yang mengejutkan karena ternyata pusaka Kembang Wijaya Kusuma dan Dewi Rukmini tidak ada di tempat. Kembang Wijaya Kusuma ternyata telah menghilang dari tempat penyimpanan (Gedong Pusoko), sedangkan Dewi Rukmini pergi tanpa pamit kepada siapapun. Kondisi ini menyebabkan Prabu Kresno merasa terkejut dan sedih yang mendalam. Kondisi hilangnya Kembang Wijaya Kusuma dan perginya Dewi Rukmini diceritakan oleh Prabu Kresno kepada pada tamu baik Pandita Durna maupun Prabu Dewo Kumoro. Kondisi ini membuat kecewa semua tamu yang hadir. Kondisi ini juga membuat saling curiga antar tamu yang hadir, terutama Pandita Durna curiga kepada Prabu Dewo Kumoro yang menyebabkan gagalnya harapan mereka untuk mendapatkan Kembang Wijaya Kusuma dan Dewi Rukmini. Untuk itu Pandita Durna meminta kepada Prabu Dewo Kumoro untuk menuju ke Alunalun negara Hastina supaya dapat saling adu kekuatan agar pesaingnya terkalahkan. Sehubungan dengan perdebatan yang terjadi di istana yang dilanjutkan dengan kedua tamu menuju ke alun-alun, menandai berakhirnya pertemuan yang diselenggarakan oleh Prabu Kresno. Untuk itu Prabu Kresno meminta kepada Patih Udowo untuk membubarkan pertemuan, serta meminta kepada Raden Haryo Setiyaki untuk mengikuti para tamu ke alunalun. Pesan Prabu Kresno yang akan disampaikan ke para tamu terkait dengan sayembara. Sayembara yang dimaksud diperuntukkan bagi tamu yang mampu menemukan Kembang Wijaya Kusuma dan Dewi Rukmini akan dipinjami keduanya untuk mengatasi adanya musibah yang menimpa kedua negara. Akhirnya Prabu Kresno kembali ke istana, sedangkan Patih Udowo bertugas membubarkan pertemuan dan Raden Setiyaki menuju ke alun-alun Dworowati untuk menyampaikan pesan dari Prabu Kresna kepada Pandita Durna dan Prabu Dewo Kumoro.

\section{b. Jejer Limbukan}

Setelah pertemuan selesai, para pembantu rumah tangga, serta pelayan kerajaan (para emban) berupaya untuk mengobati rasa penat selama mengikuti dan melayani para pembesar kerajaan selama pertemuan di istana. Pada sesi ini berupa guyonan untuk menghibur penonton maupun raja yang sedang menghadapi masalah yang terkait dengan permohonan peminjaman Kembang Wijaya Kusuma dan permaisurinya Dewi Rukmini. Pada tahap ini dalang dapat menyampaikan maksud kegiatan serta pesan moral yang diinginkan.

\section{1) Cangik}

Cangik merupakan ibu dari Limbuk yang berperawakan kecil dan kurus. Cangik biasanya yang memulai untuk kegiatan guyon maton sebagai upaya penyembuhan terhadap rasa penat setelah melayani para pimpinan di Keraton Dworowati. Cangik berupaya untuk menyanyi maupun menari dan saling menghibur agar suasana Kedaton terasa menyenangkan.

\section{2) Limbuk}

Limbuk berperawakan gemuk dan berbadan besar, walaupun demikian Limbuk 
mampu untuk berjoget dengan lincah. Diskusi antara Cangik dan Limbuk sebagai media untuk menyampaikan pesan diselenggarakannya pagelaran wayang kulit. Untuk itu melalui pesan ini menggambarkan fungsi wayang yang selain sebagai tontonan, namun juga sebagai tuntutan. Wayang sebagai tontonan karena ditonton oleh masyarakat kebanyakan. Selain itu wayang berperan penting sebagai tuntunan karena memuat ajaran yang baik mengenai perilaku bermasyarakat.

\section{c. Jejer di Alun-alun Dworowati}

Patih Sengkuni berupaya untuk mengumpulkan para senopati perang di antaranya Dursosono, Kartomarmo, Citraksi, dan Durmogati. Tujuan utama pertemuan itu sebagai upaya untuk merembug keadaan yang baru saja dialami Patih Haryo Sengkuni di istana Keraton Dworowati. Patih Sengkuni meminta mereka untuk memukul mundur Prabu Dewo Kumoro agar Kembang Wijaya Kusuma dan Dewi Rukmini dapat dipinjam oleh negara Hastina. Perkelahian antara Prabu Dewo Kumoro dengan pasukan Hastina terjadi, karena kedua belah pihak tetap menginginkan untuk memperoleh Kembang Wijaya Kusuma dan Dewi Rukmini. Akhirnya perkelahian yang terjadi di alun-alun Dworowati dihentikan oleh senopati Dworowati yang bernama Raden Setiaki. Raden Setiyaki menyampaikan pesan dari Prabu Kresna bahwa Kembang Wijaya Kusuma menghilang, serta Dewi Rukmini juga meninggalkan kerajaan Dworowati yang tidak diketahui tujuannya. Raden Setiaki menyampaikan sayembara yang bersisi bagi siapa yang mampu menemukan Kembang Wijaya Kusuma maupun Dewi Rukmini akan diberi izin untuk memanfaatkan sebagai sarana untuk mengatasi kondisi yang menimpa di negaranya. Setelah mendengar penjelasan itu, Prabu Dewo Kumoro beserta Begawan Durna meninggalkan alun-alun kerajaan Dwotowati untuk mencari keberadaan Kembang Wijaya Kusuma dan Dewi Rukmini.

\section{d. Jejer Tawang Gantungan}

Prabu Dewo Kumoro melaporkan kepada prabu Dewo Kusumo mengenai tugas yang telah dilaksanakan untuk memimjam Kembang Wijaya Kusuma dan Dewi Rukmini sebagai sarana untuk menenteramkan kondisi di negara Tawang Gantungan. Prabu Dewo Kumoro melaporkan bahwa yang bersangkutan tidak berhasil memperoleh apa yang diharapkan karena Kembang Wijaya Kusuma menghilang dari Gudang Pusaka, sedangkan Dewi Rukmini meninggalkan kerajaan tanpa memberi tahu kepada siapapun. Kondisi ini membuat curiga Prabu Dewo Kusumo yang berprasangka bahwa Prabu Kresno tidak mengizinkan untuk meminjamkan Kembang Wijaya Kusuma dan Dewi Rukmini. Berdasarkan prasangka ini Prabu Dewo Kusumo ingin merebut sendiri Kembang Wijaya Kusuma dan Dewi Rukmni dari tangan Prabu Kresna. Untuk itu didampingi Togog dan Trembilung untuk menuju negara Dworowati. Togog dan Trembilung memahami betul jalan menuju negara Dworowati. Perjalanan Prabu Dewo Kusumo diikuti oleh Prabu Dewo Kumoro beserta prajurit dari Kerajaan 
Tawang Gantungan untuk berupaya merebut Kembang Wijaya Kusuma dan Dewi Rukmini.

\section{e. Perjalanan Prabu Dewo Kusumo}

Keberangkatan Prabu Dewo Kusumo beserta pasukannya menembus hutan belantara yang diikuti oleh 2 orang penunjuk jalan yaitu Togog dan Trembilung. Prabu Dewo Kusumo di tengah jalan bertemu dengan Raden Wisang Geni. Ketika itu Raden Wisang Geni jalan bersama dengan Raden Gatotkaca. Niat jahat Prabu Dewo Kusumo diketahui Raden Wisang Geni. Pertempuran antara 2 kelompok tidak dapat dielakkan. Pertempuran dimenangkan oleh Raden Wisang Geni. Untuk itu sesuai usulan Togog, Prabu Dewo Kusumo sebaiknya meninggalkan Wisang Geni dan mencari jalan lain untuk menuju ke Kraton Dworowati agar dapat segera mencuri Kembang Wijaya Kusuma dan Dewi Rukmini.

\section{f. Goro-goro}

Goro-goro menggambarkan mengenai kondisi dunia yang sedang dilanda musibah kemudian atas campur tangan Yang Maha Kuasa kondisi yang carut marut itu menjadi kembali tenteram. Sebagai wujud ketenteraman muncul para abdi keraton yang dikenal sebagai Punokawan Catur (abdi sebanyak 4 orang) yang meliputi Semar, Gareng, Petruk dan Bagong. Mereka bersenda gurau, serta bernyanyi sebagai wujud ketenteraman hidup dan rasa senang dengan kondisi yang teteram itu. Para abdi berupaya menghibur pada satria yang diikutinya agar selalu bersifat sabar, tidak bersedih dan tetap semangat dalam menjalankan tugas negara.

\section{g. Prabu Kresno Bertapa di Gunung Selo Gilang}

Kebingungan prabu Kresno karena hilangnya Kembang Wijaya Kusuma dan perginya isteri tercinta Dewi Rukmini, menyebabkan yang bersangkutan membuat keputusan untuk pergi menuju Karang Kabulutan tempat tinggal Semar Bodronoyo untuk meminta pendapat dalam upaya mengatasi masalah yang sedang dihadapi. Berdasar saran dari Semar, untuk dapat menemukan kembali Kembang Wijaya Kusuma dan isterinya Dewi Rukmini, akhirnya Prabu Kresno bertapa di Gunung Selo Gilang untuk mendapatkan petunjuk (wangsit) dari Dewa Kahyanagan mengenai keberadaan pusaka Kembang Wijaya Kusuma dan Dewi Rukmini. Setelah memperoleh saran dari Semar, Prabu Kresna pergi meninggalkan Karang Kabulutan menuju ke Gunung Selo Gilang.

\section{h. Kresna Bertapa di Gunung Selo Gilang}

Kresno bertapa di Gunung Selo Gilang. Langkah Prabu Kresna ini menyebabkan keadaan di Kahyangan terpengaruh buruk. Untuk itu raja Kahyangan yaitu Bathara Guru mengutus Bathara Narada untuk memberikan petunjuk keberadaan Kembang Wijaya Kusuma dan Dewi Rukmini dengan memberi pusaka dengan nama Puspito Manik. Makna kata puspito berarti bunga, sedangkan manik berarti pusat atau perhatian. Untuk itu Puspito Manik mengandung makna bahwa bunga yang memiliki kelebihan dibanding bunga lainnya. Berbekal pusaka itu Prabu Kresna akan menemukan pusakanya Kembang Wijaya Kusuma dan isterinya Dewi 
Rumini. Puspito Manik ini memiliki kekuatan mampu menghidupkan makhluk yang mati, mampu membunuh orang, serta mampu menghancurkan gunung bila Puspito Manik dilempar pada sasaran.

\section{i. Pertemuan Prabu Dewo} Kusumo dengan Prabu Kresno Akhirnya Prabu Dewo Kusumo dapat mencapai negara Dworowati dan dapat menemui Prabu Kresno. Prabu Dewo Kusumo menanyakan mengenai niatnya untuk memperoleh Kembang Wijaya Kusuma dan Dewi Rukmini. Keinginan Prabu Dewo Kusumo tetap ditolak oleh Prabu Kresno. Berhubung Prabu Dewo Kusumo tetap memaksakan kehendak, menyebabkan Prabu Kresna murka dengan melempar Puspito Manik pemberian Bathara Narada pada diri Prabu Dewo Kusumo dan Prabu Dewo Kumoro. Akibat kekuatan yang luar biasa dari Puspito Manik mengakibatkan Prabu Dewo Kusumo berubah wujud seperti semula menjadi Kembang Wijaya Kusuma, sedangkan Prabu Dewo Kumoro berubah wujud menjadi Dewi Rukmini. Kembalinya Kembang Wijaya Kusuma dengan Dewi Rukmini menyebabkan Prabu Kresna merasa berbahagia. Untuk itu Prabu Kresna dengan membawa Kembang Wijaya Kusuma dan diiringi oleh isterinya Dewi Rukmini kembali menuju Keraton Dworowati untuk memimpin negara yang subur dan makmur serta mendapat dukungan dari seluruh masyarakat di lingkungan Kerajaan baik dari semua lapisan kondisi ekonomi maupun keturunan (rakyat jelata maupun darah biru). Untuk menghindari adanya ancaman dari sisa prajut dari Tawang Gantungan, dibersihkan oleh pasukan Pandawa dengan komando oleh Raden Werkudara (Bima).

\section{j. Tancep Kayon}

Sehubungan dengan keberhasilan

Prabu Kresno untuk memperoleh kembali Kembang Wijaya Kusuma dan Dewi Rukmini, Prabu Kresno mengajak semua masyarakat untuk bersyukur dalam wujud syukuran dengan mengajak makan bersama (kembul bujono atau dhahar bersama).

\section{Analisis Kandungan Pendidikan Karakter}

Nilai pendidikan karakter yang terkandung dalam wayang kulit, di antaranya:

\section{a. Religius}

Karakter reiligius ditunjukkan oleh Prabu Kresna ketika menghadapi masalah karena pusaka Kembang Wijaya Kusuma telah hilang dari Gedung Pusaka, sedangkan istrinya Dewi Rukmini telah meninggalkan Keraton Dworowati tanpa berpamitan baik dengan para Emban, juga tidak berpamitan dengan Prabu Kresna. Kondisi yang seperti ini membuat Prabu Kresna untuk bertapa di Gunung Selo Gilang. Bertapa ini sebagai wujud upaya umat manusia untuk mendekatkan diri pada Yang Maha Kuasa untuk memohon pertolongan agar dirinya mampu mengatasi masalah yang dihadapi sesegera mungkin. Prabu Kresna akhirnya memperoleh bantuan dari Dewa untuk menemukan pusaka dan isterinya.

\section{b. Jujur}

Karakter jujur ditunjukkan oleh Prabu Kresna ketika menerima tamu Pandita Durna dan Prabu Dewo Kumoro. Prabu Kresna berterus terang bahwa Pusaka Kembang Wijaya 
Kusuma telah hilang dari Gedung Pusaka, sedangkan isterinya Dewi Rukmini telah meninggalkan istana tanpa pamit dengan siapapun. Kejujuran Prabu Kresna ini awalnya menimbulkan kecurigaan bagi 2 tamu yang menginginkan pusaka dan isteri Prabu Kresna. Berkat kejujurannya itu Prabu Kresna memberanikan diri untuk memberi tahu sesuai dengan keadaan yang sesungguhnya, walaupun bisa menerima umpatan maupun cacian dari para tamunya.

\section{c. Toleransi}

Karakter toleransi ditunjukkan oleh Prabu Kresna ketika mendengar permintaan baik Pandita Durna maupun Prabu Dewo Kumoro yang berkeinginan untuk meminjam Kembang Wijaya Kusuma dan isterinya Dewi Rukmini. Bahkan pada kebanyaan keadaan, seorang lelaki akan marah ketika diganggu isterinya. Prabu Kresna tetap toleran terhadap tamu yang menghendaki pusaka dan isterinya. Prabu Kresna tetap menanggapi permintaan tamunya.

\section{d. Disiplin}

Karakter disiplin ditunjukkan oleh Raden Wisang Geni dan Raden Gatotkaca yang berupaya untuk menjaga keamanan negara Amarta maupun Dworowati. Mereka mengelilingi perbatasan negara untuk menjaga ancaman yang mungkin dapat datang dari negara tetangga.

\section{e. Kerja Keras}

Kerja keras merupakan karakter yang banyak tergambar pada para ksatria di Amarta maupun Dworowati. Seperti halnya prajurit Dworowati yang bernama Raden Setiyaki memiliki karakter kerja keras yang sangat menonjol. Yang bersangkutan berupaya seoptimal mungkin untuk menjalankan tugas yang diemban pada pundaknya. Raden Setiyaki berjuang untuk mengatasi masalah yang dihadapi oleh negara Amarta maupun Dworowati hingga titik darah yang penghabisan. Selain Raden Setiyaki, juga terdapat Raden Gatotkaca yang memiliki karakter yang hampir sama. Tugas yang diembannya harus sukses, sehingga yang bersangkutan berupaya memperjuangkannya seoptimal mungkin dengan berbagai metode maupun cara yang dapat memudahkan dalam mencapai tujuan.

\section{f. Kreatif}

Karakter kreatif sangat menonjol dimiliki oleh Semar Bodronoyo yang merupakan pamomong satriya di Amarta. Semar berupaya secara kreatif untuk memberikan masukan kepada Prabu Kresna dalam upaya menemukan pusaka Kembang Wijaya Kusuma dan isterinya Dewi Rukmini. Usulan Semar Bodronoyo yang sangat kreatif itu, akhirnya dituruti oleh Prabu Kresno untuk berserah diri kepada Dewa di Kahyangan. Serah diri ini diharapkan merupakan langkah yang cepat untuk mengatasi masalah yang sedang dihadapi oleh Prabu Kresna.

\section{g. Mandiri}

Karakter mandiri dimiliki oleh mayoritas ksatria yang ada di negara Amarta maupun Dworowati. Kemandirian ini selalu ditampilkan para ksatria ketika menjalankan tugas untuk menjaga keamanan negara. Secara mandiri mereka mampu melaksanakan tugas yang sedang diembangnnya tanpa pertolongan orang lain, walaupun mereka tidak menutup kemungkinan untuk 
mendapat pertolongan dari orang lain. Karakter ini sangat menonjol pada diri Raden Wisang Geni maupun Raden Gatotkaca. Mereka sangat mandiri dalam menjalankan tugas, walaupun di antaranya saling tolong menolong untuk memperlancar tugas yang diberikan padanya.

\section{h. Demokratis}

Karakter demokratis dimiliki oleh tokoh Prabu Kresno. Selama menemui tamu Pandita Durna dan Prabu Dewo Kumoro ditanggapinya melalui dialog yang demokratis. Walaupun Prabu Kresna banyak memberi tugas kepada adiknya yaitu Raden Setiyaki, namun apabila yang diberi tugas telah menyanggupi tugas lain akan bisa diterima asalkan diberikan informasi secara terbuka.

\section{i. Rasa Ingin Tahu}

Rasa ingin tahu sangat melekat pada diri Prabu Kresna. Bahkan Prabu Kresna dikenal sebagai orang yang waskita (Jawa: tahu sebelumnya). Prabu Kresna berupaya untuk ingin tahu keadaan di seluruh negara Dworowati dengan meminta informasi dari Patih Udawa maupun dari Raden Setiyaki.

\section{j. Semangat Kebangsaan}

Karakter semangat kebangsaan sangat menonjol dimiliki oleh Raden Gatotkaca maupun Raden Setiyaki. Mereka rela untuk berperang melawan siapapun yang berusaha untuk menggangu keselamatan negara baik Amarta maupun Dworowati. Karakter ini juga dimiliki oleh Raden Bima yang berupaya untuk mengatasi masuknya musuh dari negara tetangga maupun negara lain yang berasal dari luar pulau.

\section{k. Cinta Tanah Air}

Karakter cinta tanah air ini secara menonjok dimiliki oleh Raden Bima yang berusaha untuk mengusir maupun memukul mundur pasukan yang menyertai Prabu Dewo Kumoro maupun Prabu Dewo Kusumo dari Kerajaan Tawang Gantungan. Upaya ini dimaksudkan agar keselataman negara baik Amarta maupun Dworowati dapat dijamin kestabilannya. Raden Bima berani menghadapi musuh dari manapun demi negaranya.

\section{Menghargai Prestasi}

Karakter menghargai prestasi ditunjukkan oleh Prabu Kresna yang mengapresiasi isterinya Dewi Rukmini yang telah berupaya untuk mengikuti kepergian pusaka Kembang Wijaya Kusuma yang telah berubah menjadi Prabu Dewo Kusumo dengan menyamar menjadi Prabu Dewo Kumoro.

\section{m. Bersahabat/Komunikatif}

Karakter bersahabat ditunjukkan oleh ksatria Amarta yang selalu akrab dengan pada pembantunya. Raden Arjuna sangat dekat dengan Semar Bodronoyo maupun Gareng, Petruk dan Bagong. Karakter bersahabat ini ditunjukkan dengan tidak memarahinya ketika pada abdi melakukan kesalahan, namun Raden Arjuna hanya memberi sinyal yang sangat halus agar pada pembantunya melakukan perubahan perilaku.

\section{n. Cinta Damai}

Karakter cinta damai dimiliki oleh Prabu Kresna. Walaupun demikian bila ada musuh yang datang yang bersangkutan harus bisa 
menghadapinya. Seperti kedatangan Prabu Dewo Kumoro harus dihadapi melalui perang ketika telah mengancam atau berpotensi menganggu ketenteraman masyarakat atau bahkan mengancam keselamatan negara.

\section{o. Gemar Membaca}

Makna membaca tidak selalu hanya berkaitan dengan membaca buku, majalah maupun bacaan lainnya. Membaca memiliki makna kemampuan seseorang untuk melihat situasi yang dihadapi, sehingga keputusan yang dilakukan tepat sasaran terutama yang terkait dengan kebaikan umat manusia. Prabu Kresna memiliki kemampuan untuk membaca situasi yang terjadi di alun-laun Kerajaan Dworowati yang terjadi pertengkaran antara Prabu Dewo Kumoro dengan Pandita Durna. Kondisi ini diselesaikan melalui adanya janji meminjamkan Kembang Wijaya Kusuma maupun Dewi Rukmini bagi siapapun yang mampu menemukannya. Melalui janji ini kedua belah pihak menerima dan pertengkaran berakhir.

\section{p. Peduli Lingkungan}

Karakter peduli lingkungan ini tidak menonjol ditunjukkan oleh para tokoh yang tampil pada lakon Puspito Manik.

\section{q. Peduli Sosial \\ Karakter peduli sosial} ditunjukkan oleh Raden Setiyaki yang berupaya untuk menciptakan kondisi masyarakat yang damai dengan cara memisah pertengkaran antara Prabu Dewo Kumoro dengan Pandita Durna.

\section{r. Tanggung Jawab}

Karakter tanggung jawab dimiliki oleh Raden Gatotkaca dan raden Wisang Geni. Mereka menjalankan tugas untuk menjaga keamanan negara dengan rasa tanggung jawab. Masuknya perusuh dari luar negara menjadi tanggung jawab mereka, sehingga mereka akan berupaya semaksimal mungkin untuk menjaga keamanan negara.

\section{Integrasi Pendidikan Karakter di SMP}

Pendidikan karakter harus mampu diimplementasikan melalui proses integrasi dalam pembelajaran di SMP. Integrasi itu dapat dilakukan melalui mata pelajaran, di antaranya:

\section{a. Pendidikan Kepribadian}

Proses integrasi pendidikan karakter dalam mata pelajaran seperti Pendidikan Kewarganegaraan, Agama maupun Bahasa Indonesia dapat dilakukan secara langsung. Kewarganegaraan mampu membentuk karakter tanggung jawab, cinta tanah air dan semangat kebangsaan. Mata pelajaran Agama mampu membentuk karakter jujur. Bahasa Indonesia mampu membentuk karakter peduli lingkungan.

\section{b. Mata Pelajaran Bahasa Indonesia \\ Integrasi pendidikan karakter} dapat dilakukan melalui mata pelajaran Bahasa Indonesia. Proses integrasi pendidikan karakter dalam mata pelajaran Bahasa Indonesia disesuaikan dengan sifat karakteristik mata pelajaran yang bersangkutan. Untuk itu kreativitas guru Bahasa Indonesia sangat penting dikembangkan dalam rangka untuk 
mengintegrasikan pendidikan karakter dalam mata pelajaran.

\section{1) Integrasi Parsial}

Pendidikan karakter diharapkan dapat diintegrasikan secara parsial di dalam mata pelajaran Bahasa Indonesia. Perlu ditekankan bahwa tidak semua karakter dapat diintegrasikan secara bersamaan di dalam mata pelajaran, namun proses integrasi dapat dipilih sesuai dengan karakter yang paling sesuai dengan materi yang sedang dibahas selama pembelajaran.

Karakter yang diintegrasikan di dalam pembelajaran Bahasa Indonesia harus difokuskan pada karakter tertentu. Tidak memungkinkan bila semua nilai karakter dibebankan untuk diintegrasikan dalam sebuah mata pelajaran. Seperti karakter tanggung jawab dapat diintegrasikan melalui kegiatan kerja kelompok, sehingga penilaian terhadap karakter dapat dievaluasi selama proses pembelajaran berlangsung.

\section{2) Integrasi Praktis}

Selain pada pertemuan selama pembelajaran di kelas, proses integrasi pendidikan karakter dalam mata pelajaran juga dapat dilakukan secara pratis. Ketika membaca puisi pesanpesan karakter dapat disampaikan dengan menarik, sehingga mampu meningkatkan perhatian peserta didik.

Selain dalam bentuk pebacaan puisi, guru Bahasa Indonesia dapat menanamkan nilai karakter selama berinteraksi secarar langsung seperti ketika berkonsultasi yang terkait dengan tugas mata pelajaran Bahasa Indonesia. Konsultasi semakin efektif ketika frekuensi meningkat.

\section{PENUTUP}

Berdasarkan hasil penelitian dan pembahasan, dapat diambil kesimpulan bahwa wayang kulit berperan sebagai tontonan, sekaligus tuntunan. Tontonan karena wayang kulit dapat dinikmati oleh seluruh lapisan masyarakat, sedangkan tuntunan karena mengandung pesan moral yang disampaikan oleh seorang dalang yang terkait dengan perilaku bermasyarakat, termasuk berbangsa dan bernegara bahkan juga terkait dengan bela negara. Seluruh nilai karakter yang meliputi: 1) religius, 2) jujur, 3) toleransi, 4) disiplin, 5) kerja keras, 6) kreatif, 7) mandiri, 8) demokratis, 9) rasa ingin tahu, 10) semangat kebangsaan, 11) cinta tanah air, 12) menghargai prestasi, 13) bersahabat/komunikatif, 14) cinta damai, 15) gemar membaca, 16) peduli lingkungan, 17) peduli sosial, serta 18) tanggung jawab terkandung di dalam wayang kulit dengan Lakon Puspito Manik yang diperankan oleh masing-masing tokoh yang berbeda.

\section{DAFTAR PUSTAKA}

Kilpatrick, W. (1992). Why Johny Can't Tell Right From Wrong. New York: Simon \& Schuster, Inc.

Lickona, T. (1992). Education for Character. New York: Bantam.

Marianto, D.H. (2008). Pendidikan Karakter, Paradigma Baru Dalam Pembentukan Manusia Berkualitas. Diakses pada 10 Januari 2011 dari http://tumoutou.net/702_05123/dwi_ hastuti.htm.

Megawangi, R. (2008). Membangun SDM Melalui Pendidikan Holistik Berbasis Karakter. Diakses pada 11 Januari 2011 dari http://keyanaku.googlepages .com/pe ndidikanholistikberbasiskarakter.pd

Otten, E.H. (2000). Character Education. Diambil pada 10 Januari 2011 dari 
http://www.indiana.edu/\%7Essdc/ch arding.html.

Santrock, J.W. (2014). Educational Psychology. Jakarta: Salemba Humanika. 